\title{
Working in a Group before Meeting Face-to-Face - A Case of International Student Online Project
}

\author{
Hong Wu and Gunnar Andersson \\ Østfold University College \\ Sarpsborg, Norway
}

hong.wu@hiof.no gunnar.andersson@hiof.no

\author{
Mathias Wilichowski \\ University of Wismar \\ Germany
}

m.wilichowski@mb.hs-wismar.de

\begin{abstract}
This paper describes a case of an international student online project. The project was a part of cooperation between two European educational institutions, Østfold University College in Norway and University of Wismar in Germany. An international student group consisting of three German students and five Norwegian students joined this project. Technically, the project was testing of an open source based online platform, LearnLoop (http://www.learnloop.org/). Organizationally, the project was used as a preparing phase for German visiting students, as well as international openings for Norwegian students. The project topic was focused on international communication and environment issues. As a result, the German students were able to getting familiar with Norway and Norwegian education system, and working methods. The Norwegian students also acquired international experiences by working this project with their German costudents. This paper describes the process of this joint international student project, and presents the detailed analysis of online activities, as well as offline student activities throughout the project phases.
\end{abstract}

Keywords: Open source platform, international student exchanges, network cooperation, student activities

\section{Introduction}

The European Union has launched a number of programs for the integration and cultural understanding between EU members, none members and associated members. The Program Socrates is the one that focuses on the international staff and student exchanges between the educational institutions in Europe. Two of European educational institutions, Østfold University College of Norway and University of Wismar of Germany, joined this program. The staff cooperation and regular exchange program between these two institutions has initiated and continued since 1995, and the benefits were received for both sides. There are activities like staff visiting annually and visiting lectures have been thematically focused on many fields, among these, online teaching and learning. This paper describes a case of online cooperation applied as preparing work before ex-

Material published as part of this journal, either on-line or in print, is copyrighted by Informing Science. Permission to make digital or paper copy of part or all of these works for personal or classroom use is granted without fee provided that the copies are not made or distributed for profit or commercial advantage AND that copies 1) bear this notice in full and 2) give the full citation on the first page. It is permissible to abstract these works so long as credit is given. To copy in all other cases or to republish or to post on a server or to redistribute to lists requires specific permission from the publisher at Publisher@InformingScience.org

\section{change students started their visits to} the host institution. 


\section{An International Student Exchange Project}

This project was initiated to combine an online solution into a student exchange program. Both institutions have had a number of exchange activities, both for teaching staff and students. A group of three Wismar students planed to stay at Østfold University College in autumn 2003. It was then initiated an idea to introduce and guide the visiting students to Østfold University College online. In this way, the students would be better prepared before their actual visit to Norway. This online introduction was accomplished through the students' participation into an online course, held by Østfold University College. The Germany students were arranged into a working team together with Norwegian students. The objectives of such an arrangement are:

For German students from University of Wismar:

- Getting familiar with host institution and its systems

- Getting familiar with host country and local information

- Getting familiar with working methods at host institution

- Being well prepared for cultural shock or uncertainties

For Norwegian students at Østfold University College:

- Developing international competence and skills

- Learning communications to other people, especially people with different cultural and educational backgrounds

- Learning different working methods and other scholar philosophies

- Learning team work and international project skills

The arrangement was fulfilled through an online course in "Communication, Environment and Project (CEP)" held and conducted at Østfold University College. The CEP course is a general and entry leveled course for engineering students. It has an objective to teach the students' communication skills with focuses on project-based learning. Students are organized into groups to work with environment related case projects. These cases are usually picked up from local industrial companies. CEP is estimated as 15 ECTS (European Credit Transfer System) points.

The course is linked to textbooks and practiced in cooperation with nearby companies. Student groups shall address company situations relevant to chapters in the textbook, describe, analyze, compare to theory and recommend for the company in small reports (3-5 pages). Second half of the course they shall make a project work on an environmental task for the company. For the project they are asked to act as consultants, make plans, budgets, accounting, and they shall report and present their work, result and recommendations. The intention is that this shall be valuable for the company without any direct payment.

Though the course is developed primarily for engineering students, it also has relevance for all other professions. Communication and cooperation are basic skills for everybody, and all active society workers should be conscious of the impact of their decisions and actions to our common environment. It is necessary to have attitudes to the environment and basic project management skills are required for any professions in the future.

The CEP is a project based course, so the major part of activities is project conducting. This provides a perfect opportunity for our international student project group to assign the project task, which was a comparative analysis for air quality for a sampled German local school versus a sampled Norwegian local school. It was the CEP intention that such project should be local related, but international comparatively. It is the essential element and key success criteria to understand local culture and industrial knowledge for international business operations. Learning of local cultures and companies will be the main thematic subjects for such a CEP project. 


\section{An Open Source Based Online Solution}

The standard CEP course for other Norwegian engineering students has converted into a virtual classroom. It was used the courseware LearningSpace (IBM Lotus software, 2003), as an online communication centre. This was combined with traditional teaching, consulting and advising throughout the course for these Norwegian students.

For this particular international student program, the current arrangement only adopted the content of CEP, but used another platform LearnLoop. It is an open source based platform, developed Gothenburg University of Sweden (LearnLoop, 2003). The primary intention of using an open source solution was to avoiding licenses issue, as LearningSpace is a licensed courseware and requires permit for other users than buyer.

There are several advantages for using such an open source based online solution, especially for cooperation between these two educational institutions:

- Free of charge

- No demanding for a powerful server

- Easy to learn and administer the courseware

- Easy to install a local server, so the courseware server can be installed anywhere in the world

- Access and possibility for changing and modifying the functions and usage limits

Organizing of CEP for this particular international student group began in a remote scale and therefore conducted online through LearnLoop. First, German visiting students were enrolled into the CEP course online from Germany. They were assigned with a selected group of Norwegian students, so they could work together in a same project group. It was initiated with exchanges of ordinary emails, but the communication gradually moved into the actual courseware LearnLoop.

It is basically important to create an e-learning environment (Jain, Howlett, Ichalkaranje \& Tonfoni, 2002; Palloff \& Pratt, 2003) no matter which platform is used. Before this project, the current open source solution LearnLoop has been pre-tested through a number of course activities internal at Østfold University College. The general feedback among the students and teaching staff, comments and user experiences so far are mostly positive for implanting of such open source solutions.

Furthermore, it has been used visual and synchronous communication solutions, such as direct online meetings. There were 2-3 such online direct meetings held between Germany and Norway throughout the project period. Among these, it was the first project meeting and the final project presentation, where the German and Norwegian students presented their final project reports each other through such a direct meeting. This was a multimedia-based approach to stimulate and backup the communication between the students (Naidu, 2003). MS-NetMeeting and PolyView are the two available and used solutions for such communication.

\section{The Process of Online Project Teamwork}

The actual process of online project teamwork lasted from January and to May 2003. The virtual classroom of LearnLoop is much similar as any other online platform in organization of messages and documents. The students have created the following 5 subfolders to categorizing their message and documents:

- Forum - An asynchronous discussion forum with chronological order (45 messages).

- Diary - A message board for daily notes and general information (7 notes)

- Meetings - A folder to file the meeting journals (18 journals) 
- $\quad$ Files - A folder for project presentations and progress reports (13 reports and 2 self-created web sites)

- Hand-in - A folder for the final reports, appendices and attachments (6 attachments)

The Forum is the natural place where the students started their communications each other. It is also a virtual place where they can freely write their spontaneous reactions and thoughts. It is therefore also an interesting place to analyze the process of online project teamwork.

The communication between the students was initiated with simple and careful messages. The activity level was relatively modest and the message content was rather simple, see details in Figure 1. There were only 9 messages in total and thee were sent over 3 active days.

It was also noticed that the Norwegian students were the only actors for this period, as German students were not able to accessing online due to their school vacations. One of visiting student noticed this situation from Germany early in December 2002. There seemed to be however a weakness of communication or backup action, so the real connection between German and Norwegian students was not settled until later February. The detailed messages are citied in Table 1.

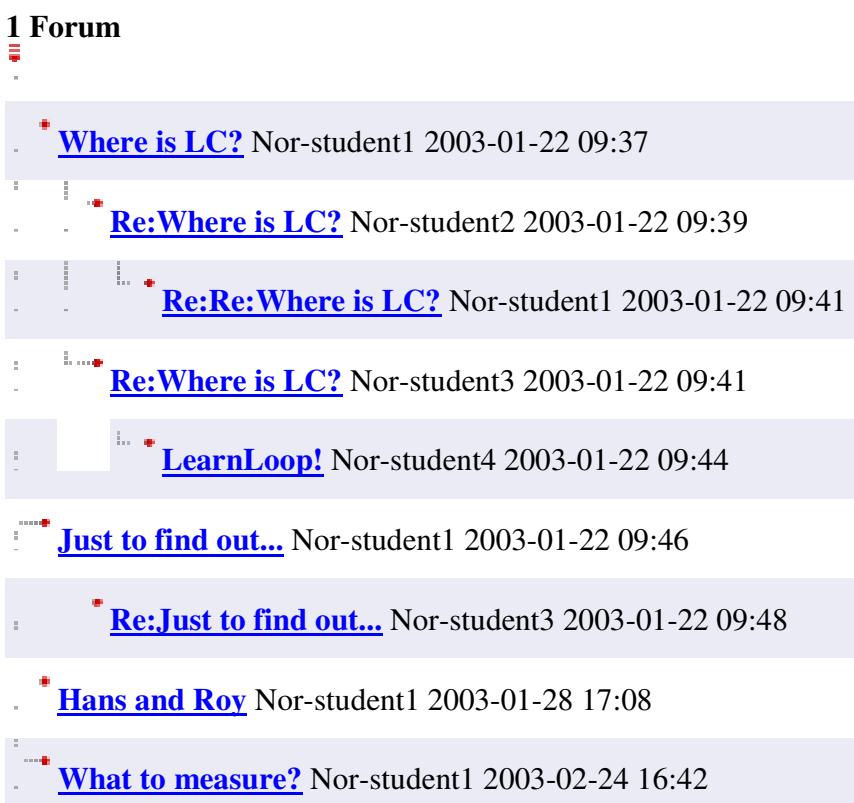

What to measure? Nor-student1 2003-02-24 16:42

Figure 1. The online activity in Forum folder for January and February 2003

The observations and interviews with key project students also confirmed this problem. The communicational activities for this period were mainly concentrated on a level between supervisors and coordinators of both institutions. The students were not informed for detailed changes yet, so the process of online teamwork

Table 1. The messages of initial online contacts for the project group

\begin{tabular}{l|l}
\hline $\begin{array}{l}\text { December 3, } \\
\text { 2002: Email by } \\
\text { Ger-student1 }\end{array}$ & $\begin{array}{l}\text { "on february there are vacations at } \\
\text { our university. so we can not be } \\
\text { online. we hope there is no problem } \\
\text { in reference to the project". }\end{array}$ \\
\hline $\begin{array}{l}\text { January 28, } \\
\text { 2003: }\end{array}$ & $\begin{array}{l}\text { Hi. I saw you were registred as } \\
\text { course members. So? What do you } \\
\text { think about the system? I just handed } \\
\text { by Nor-student1 } \\
\text { in a presentation of the group under }\end{array}$ \\
\hline $\begin{array}{l}\text { March 3, 2003: } \\
\text { LearnLoop note } \\
\text { by Ger-student1 }\end{array}$ & $\begin{array}{l}\text { We agree to your plans.... We will } \\
\text { begin our measure next week...10.03. }\end{array}$
\end{tabular}
was rather slow. For a while, few students believed their teammates in the other side were not active at all, which was not in case for this project. This could be avoided by better communication for a student level at the beginning. Other problems for initial phase of this project could also be mentioned, such as:

- Lack of motivation and initiative for participating of this international student project among many other Norwegian students due to their uncertainties for own English language skills 
- Lack of a direct training session for introduction and use of LearnLoop, especially for our German students

- Lack of coordinating and modifying for different school system and semester calendar system for students from both sides

- Lack of a backup-plan or a secondary option for student communication. The email and LearnLoop were the only alternative for them

For further improvement, there has to be establishing an incentive system to attracting and rewarding more students to this kind of project. It should budget a standard training session of introduction and use of LearnLoop, and sufficient time sources for learners. It requires normally 1014 training hours for a learner to be familiar with a new courseware. There is a need to mapping the different school system and semester calendar system, and making a flexible student exchange arrangement is the next change. A backup plan and secondary option, such as a cell phone or a SMS message is always to have when the email is not working or the courseware is still unknown for new beginners.

\section{The Cooperation of this Online Project Team}

Despite of facing the communication difficulties and delay of operation, the process of this online project teamwork accelerated drastically for the March month. There were totally 19 messages in this forum, sent over 10 active days in March 2003. The progress could also be noticed by their message topics and titles, such as:

- Measures

- $\mathrm{CO} 2$ concentration

- Opinion poll

- Net meeting

- Project Plan Air-Q

This phenomenon indicated the improvement of quality for the messages and discussions for the students. Their conversations and communication content were more focused on their project details and their teamwork. The intention of using LearnLoop forthis project was finally realized.

Another remark of online activities for this month is much more online messages forwarded by the Germany students in this forum. The total 19 sent messages has the following distribution:

- Ger-student 1 sent 9 messages

- Nor-student 1 sent 5 messages

- Nor-student5 sent 1 message

- Nor-Professor2 sent 4 messages

By now this online project team seemed to be cooperated well and productive for their tasks.

Their messages were also thematically focused on and targeted to the problems
Table 2. Selected online dialogs in the project group

\begin{tabular}{l|l}
\hline $\begin{array}{l}\text { Ger-Student1 } \\
23: 56-03-06\end{array}$ & $\begin{array}{l}\text { opinion poll measurement } \\
\text { Maybe you can tell us something about } \\
\text { it... }\end{array}$ \\
\hline $\begin{array}{l}\text { Nor-Student5 } \\
\text { 03-07 14:20 }\end{array}$ & $\begin{array}{l}\text { Re:opinion poll measurement } \\
\text { Hey Hans! We have written down some } \\
\text { questions concerning indoor climate. } \\
\text { These questions are going to be used as } \\
\text { an opinion poll among the pupils. Doing } \\
\text { this will give us some clues about what } \\
\text { is important and how to adjust the tests } \\
\text { according from necessity. }\end{array}$ \\
\hline $\begin{array}{l}\text { Nor-Student2 } 2003-04-08 \\
11: 10\end{array}$ & $\begin{array}{l}\text { data exchange } \\
\text { We where wondering when u might have } \\
\text { some of data from measuring ready, } \\
\text { since we need to exchange it to finish } \\
\text { the prosject. And we would like too fin- } \\
\text { ish soon. }\end{array}$ \\
\hline $\begin{array}{l}\text { Ger-Student1 } \\
\text { replied 2003-13 15:33 }\end{array}$ & $\begin{array}{l}\text { Reply Re: data exchange } \\
\text { Hi Olav, we have some data... I linked } \\
\text { our homepage (files). In the moment the } \\
\text { english version is not aviable. It will } \\
\text { happen next days... On this HP you will } \\
\text { find some data. We have our Online- } \\
\text { Meeting next week. so we can talk about } \\
\text { the results } \text { i think.... have a nice time,... }\end{array}$ \\
\hline
\end{tabular}


and discussions for the project details, as a conversation citation demonstrated in Table 2.

The dialogs illustrated a noticeable progress and relevance of the communication between students. Their dialogs are much more thematically focused and reciprocally based. It was dominated by the information exchanges and team cooperation. This is one of the project objectives expected, thus practicing teamwork and international project skills. It was however pointed out lately by the students that the bilateral cooperation could have been reached better, if such information exchanges started early or frequently.

\section{The Statistical Summary for Online Activities}

It is indeed an important aspect for the analysis to exam the frequency of online asynchronous activities. A description tells the quality, but a number tells the quantity. Only a combination of both will compose a complete and real analysis.

The courseware LearnLoop has a database that registers any online activities in the virtual classroom, even for each day, each person, and each folder. It is a kind of online automatic log. A great advantage of such an automatic log is the availability (easy for retrieving) and validity (direct recording) for the information sources, which creates a perfect access for a quantitative analysis. It is therefore used as a powerful instrument for the statistical summary for online activities.

There are few categories for the online log of the courseware LeranLoop, each with their own definition as follows:

- An active user is an online user, a student or a instructor, whom, either participate in and contribute with messages or documents, or read the content in a virtual classroom.

- $\quad$ Total number of logins describes the total frequencies of online visits for the entire period in a particular folder, either in Forum, Diary, Meetings, Files or Hand-in.

- Number of posting users reflects the total active users whom have sent at least a message or document for the entire period in a particular folder.

- $\quad$ Total postings indicate the number of total messages or documents are sent for the entire period in a particular folder.

For active users, it is a combination of contribution and read only activity. This combination can be compared with a similar situation in a traditional classroom. An online user has visited the virtual classroom once or many times, either contributes a message, a document or merely read the course's content online. Both activities will qualify the definition of active user. The situation can be compared with a traditional classroom, where both a talkative and a silent student will be equally counted as active students due to their appearance in the class.

For number of posting users, the definition can be imitated as a similar situation in a traditional classroom. A posting user will then be anyone whom is active in a class, either speaking or lecturing a topic, writing a note or an equation on the blackboard, raising up a question for teacher or classmates, or discussing with other classmates, etc. A posting is therefore a writing action, a message or document in an asynchronous virtual Table 3. The statistical summary for online activities particularly in Forum folder classroom.

\begin{tabular}{l|c|c|c|c}
\hline & Total & Nor & Ger & Teacher \\
\hline Active users (login): & 12 & 5 & 3 & 4 \\
\hline Total nr of logins: & 387 & 161 & 121 & 105 \\
\hline Nr of posting users: & 9 & 5 & 2 & 2 \\
\hline Total postings: & 45 & 23 & 17 & 5 \\
\hline Ave.login/ activ.user & 32 & 32 & 40 & 26 \\
\hline Ave.post./activ.user & 4 & 5 & 6 & 1
\end{tabular}


Table 3 illustrated the statistical summary for online activities in Forum folder throughout the course period. There are totally 12 online users registered throughout the course period, 3 German students, 5 Norwegian students, 1 German professor, and 3 Norwegian professors.

Reviewing this particular summary, the following remarks for online activities can be mentioned for this folder:

- Everyone, German students, Norwegian students and professors from both sides have been active users for this particular folder

- The general login activities seem to be good and equal for each group of users. This means everyone is active in visiting of the virtual classroom of this course

- Most users have contributed their writings to the course, except one Germany student and two professors

- The average contributions of posting users seem to be relatively equal between the German students and the Norwegian students.

As mentioned early, a Forum in the LearnLoop is an asynchronous discussion forum with chronological order. Examining the online activities in this folder is a good way to show the process and development of this online project teamwork.

LearnLoop contains other folders, as Diary, Meeting, Files and Hand-in, each with a number of messages, documents and reports. Examining the online activity levels in these folders will provide us a scenario of entire project work and the significant efforts and emphasis to each phase and subtask of throughout the project period.

Table 4 has summarized online activities generally in each folder of the virtual classroom for the course, inclusive Forum folder. It is a natural factor that frequencies of total logins appear to be extremely high compared with other types of activities, as the definition describes: The number of logins indicates the total frequencies of online visits, while posting is something has to be done.

Measured by the statistical summary,

Table 4. The statistical summary for online activities generally in each folder

\begin{tabular}{l|c|c|c|c|c}
\hline & Forum & Diary & Meeting & Files & Hand-in \\
\hline Active users(login): & 12 & 12 & 12 & 12 & 12 \\
\hline Total nr of logins: & 387 & 137 & 265 & 265 & 101 \\
\hline Nr of posting users: & 9 & 3 & 1 & 4 & 2 \\
\hline Total nr of postings: & 45 & 7 & 18 & 15 & 6 \\
\hline Ave.login/activ.user & 32 & 11 & 22 & 22 & 8 \\
\hline Ave.post./post.user & 5 & 2 & 18 & 4 & 3
\end{tabular}
the highest online activity level seems to belong to the Forum folder. This folder contains highest frequencies of logins, posting users, total postings, and average postings of each active user.

The only exception is the frequencies for average postings of each posting user, which is dominated the folder of "Meeting". This is because there was only one posting user for Meeting folder, and it was a Norwegian student whom took the responsibility alone for filing the meeting journals. For this case, the statistical measurement brings no significant indication.

Aside of Forum folder, "Meeting" and "Files" seem to be the two popular folders for online visitors. This significant difference can be read by their total of logins $(265,265)$, their total postings $(18,15)$, their average logins of each active user $(22,22)$ and their average postings of each posting user $(18,4)$.

Actually, these two folders contain the most importance documents (meeting journals, project presentations and progress reports) for the project. It is therefore reasonable to observe more frequent visits in these two folders. 
Figure 2 shows an illustrative summary and a figurative comparison of the same statistical summary for online activities generally in each folder. Total logins were not taking in to the figure since this activity operates with another dimension of frequency level, and will not be compatible for the comparison.

By comparing online activity frequencies in these different folders, it seems to be possible to portray a rough line for the activity frequencies for these folders. Their activity intensities can therefore be reflected through this rough line of the activity frequencies, as the following order:

- Forum contains the most intensive online activities, followed by Meeting, Files, Diary and Hand-in.

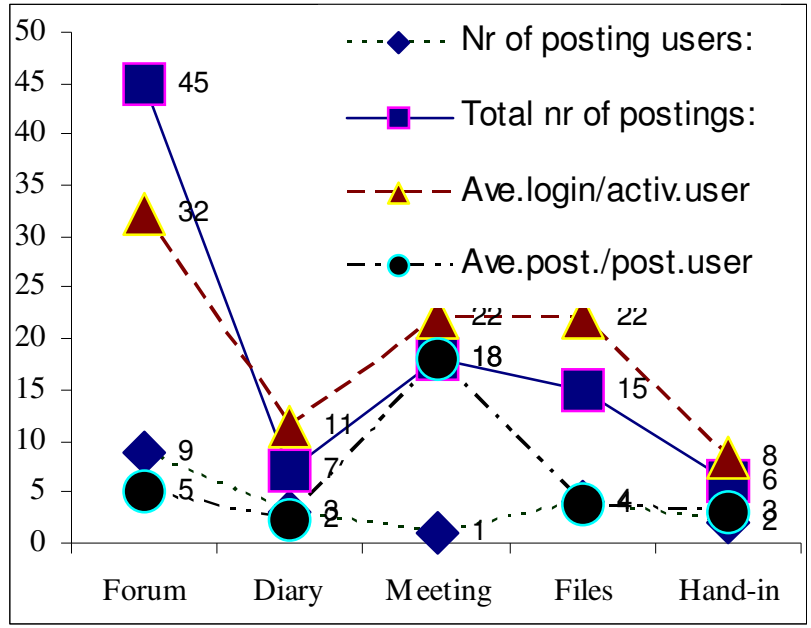

Figure 2. The figurative comparison of statistical summary for online activities generally in each folder

This order of intensities indicates the student activities in a project environment and a teamwork situation elsewhere. The equivalent priority order for project activities will then be discussions, meeting journals, progress reports, project presentations, message notes or general information, and appendices or attachments. See definitions of 5 folders early in this paper and a change of the order below:

- Forum - An asynchronous discussion forum with chronological order (45 messages).

- Meetings - A folder to file the meeting journals (18 journals)

- Files - A folder for project presentations and progress reports (13 reports and 2 self-created web sites)

- Diary - A message board for daily notes and general information (7 notes)

- Hand-in - A folder for the final reports, appendices and attachments (6 attachments)

\section{The Outcomes of this Online Project}

Concerning outcomes of the project, it is rather interesting to exam the documents and content of File folder, since this folder contains the most actual documents for the project outcomes.

Figure 3 illustrated the documents and content in File folder, where it contains 13 writing documents and 2 web sites links.

There is a good reason to believe both Norwegian and German students contributed equally to the content of this folder. Students from both sides have created their own web sites to sharing the information and presenting the project outcomes. The Germany students contributed 7 reports while the Norwegian students had 6.

As mentioned early, the process of this project teamwork was delayed at the beginning phase, so the German students were not able to fully involve in the project at the beginning. This situation was also illustrated by their documents in this folder, which were all submitted after February. Most of their documents were also focused on the late stage of the project. 
Their Norwegian teammates submitted documents in this folder rather in an earlier stage and the focus was mostly direct to presentation, group contract and project plan. The Norwegian students have actually submitted their project reports and presentations in Hand-in folder.

Actually, the Norwegian students were the only contributors to Meeting folder and Hand-in folder, while the German students used File folder solely to submit their contributions. Basically, this is only a definition issue, so it was not the crucial concern for where exactly a document should be submitted. However, this different submission practice for both sides revealed the need for further detailed communications between students of both sides, so the submission practice can be the same.

About the technical outcomes of the project, both sides have submitted detailed analysis reports for air quality at sampled school buildings, respectively from locals in Germany and Norway. The purely technical analysis was sufficiently good for both sides. However, there was a criticism for the lack of communication and cooperation during the field questionnaire design stage, so both sides used their own designed questionnaire, not codesigned one. It was therefore hard to combine and compare the measures from both sides.

An interesting and significant step of this project was the final project presentation for supervisors and professors from both institutions. The presentation was accomplished through IP

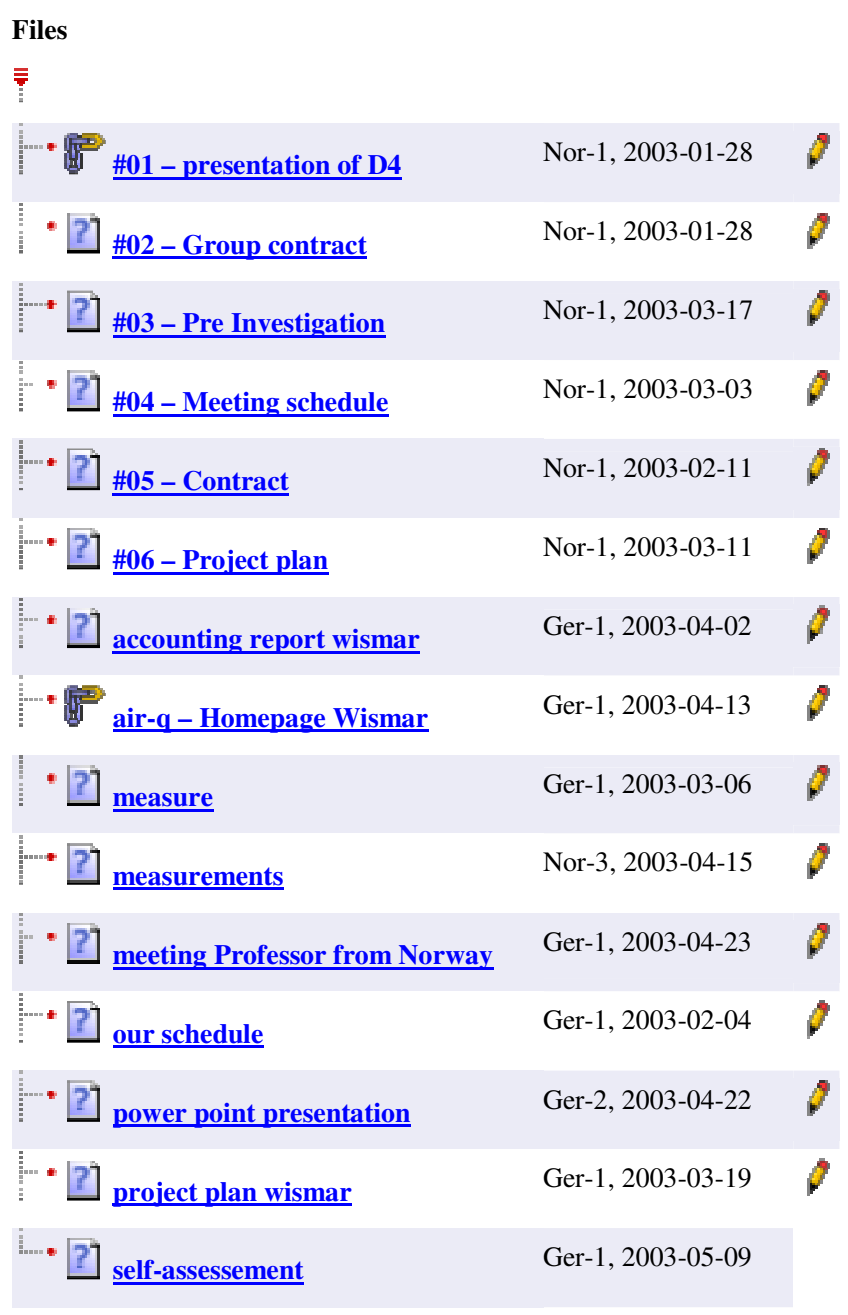

Figure 3. The documents and content in File folder based online picture-phone. The students and professors from both sides were gathered at the final presentation day, and used this solution as a direct meeting instrument. The students from both sides presented their part of the project in turn, so the professors and students in the other side questioned the presenters. The professors and censors evaluated then the presentations. The final evaluations were given combined with project report reviews afterward. MS-NetMeeting and PolyView were the two used solutions and both worked quite well during the meeting. 
After 3 months, the German students were arrived to Østfold University College and started their exchange stay in Norway. This online project with Norwegian students was a good part of the preparing work. They learned useful experiences and good knowledge about Norway, and how to work together with Norwegian students. In a way, they were better prepared to tackle their first days/weeks in Norway. They also submitted a self-assessment for this online project, indicating their own opinions for their positive and negative experiences during the project. A brief summary of the self-assessment is illustrated in Table 5.

By now their exchange plan was successfully accomplished. One of these students did actually enjoy his stay in Norway so much that he decided to extend his visiting program for another 6 month to sign up few more other courses at the host institution. He learned good Norwegian speaking as well, so he be-

Table 5. A brief summary of the self-assessment made by the German students for the project

\begin{tabular}{l|l}
\hline & $\begin{array}{l}\text { Cooperation with Norway (online), lessons for- } \\
\text { eign things topic, online meeting - } \\
\text { The topic was very interesting. The support by } \\
\text { our university is very good. Thanks to our profes- } \\
\text { sor. }\end{array}$ \\
& $\begin{array}{l}\text { The internet wiring is very interesting with Nor- } \\
\text { way. } \\
\text { Learnloop is very good to work on this project. It } \\
\text { is very simple and easy to use. } \\
\text { We are very satisfied with our results and it has } \\
\text { made much fun to us. }\end{array}$ \\
\hline & $\begin{array}{l}\text { Unfortunately, we had a little time. Could man- } \\
\text { age the project only at the same time. } \\
\text { No CO2 measuring possible. }\end{array}$ \\
& Perhaps sometimes to little exchange between the
\end{tabular}
came "an ambassador" for further student exchange programs between the two institutions.

\section{Conclusions and Further Improvement}

After all, this online project has been an interesting and beneficial experience for the students and professors in both sides. As our German students indicated in their self-assessment, the project was interesting, fun and important for cooperation with other countries. This project has demonstrated a possible future cooperation pattern, where Internet is heavily involved in (Amor, 2002). However, there are potential aspects for improvement for the future work as well.

Reviewing the intention, process observations, feedback and analysis of the project, there are few lines need to be drawn as the final conclusions:

1. It is the good practice to enroll the international visiting students into the teamwork with host students before their arrival, and this teamwork can be conducted online

2. Using open source platform is a simple option for such teamwork online, and the courseware should be simple and easy to use, preferably attached with a training course for beginners

3. Communication and information exchanges are the crucial issue at the beginning stage, since many details need to be settled or changed

4. Direct online meetings such as videoconferences, or IP based online picture-phone solutions are important for initiating, stimulating accelerating the communication process for both sides

5. It is important to motivate students to communicate each other online, so that students feel interesting not only for the project, but also having fun and social contact.

There were early mentioned few elements need to be improved, as missing for a direct training session for use of LearnLoop, especially for our German students, weak communication and information exchanges at the beginning, and without a backup-plan or a secondary option for student communication. Consequently, these weaknesses caused process delay and misunderstand- 
ing at few detailed tasks during the project work. For further improvement, there might be practi cal to suggest these implications:

- Continuing supervising and following up for student teamwork activities both online and offline

- Conducting user surveys frequently in order to retrieve feedback and comments quickly and in time

- Undertaking periodical analysis of online activity statistics and virtual class performance, and use the results to motivating or encouraging the students

- Exchanging rapidly information and user experience between student teams and teachers

- Arranging monthly or quarterly direct online meetings between teachers in updating of progress for student teamwork

There is one phrase to summarize our own experience of online teaching and learning practice for last couples of years: There is a so little detail you need to miss for things going wrong, but there are so many details you need to do properly for things going well. It seems this experience also applies well for our case of international student online project.

\section{References}

Amor, D. (2002). Internet future strategies. How to pervasive computing services will change the world. Upper Saddle River, New Jersey 07458.

IBM Lotus software (2003). http://www.lotus.com/products/learnspace.nsf/wdocs/homepage

Jain, L.C., Howlett, R.J. Ichalkaranje, N.S. \& Tonfoni, G. (2002). Virtual environments for teaching \& learning. World Scientific Publishing.

LearnLoop. (2003). http://learnloop.sourceforge.net/

Naidu, S. (2003). Learning \& teaching with technology. Principles and practices. London and Sterling. Kogan Page.

Palloff, R.M., \& Pratt, K. (2003). The virtual student. A profile and guide to working with online learners. San Franciscon, Jossey-Bass.

\section{Biographies}

Hong Wu is an associate professor at Østfold University College, Faculty of Engineering in Sarpsborg, Norway. He received his PhD (Doktor ingeniør) in project organization in 1992, at Norwegian University of Science and Technology (http://www.ntnu.no/indexe.php).

$\mathrm{He}$ is currently teaching these courses: Innovation and Product Analysis; Marketing Management. His research interests focus on topics of online teaching and learning, data analysis, and developing of online courses. For the last 10 years, he has also taught and worked with topics of Organizational Theories, Total Quality Management, Project Management and Cross-Cultural Analysis in Business Applications.

Contact phone: + 47691040 72/fax: + 4769104002

E-mail: hong.wu@hiof.no http://www.ir.hiof.no/ hwu/Main/home.htm

Gunnar Andersson is an assistant professor at Østfold University College. He is an online instructor for a number of the college's online courses. He is also the project manager for the college's online course activities. He has working experience from IBM Learning Services as an IT Pedagogical Consultant on Distributed Learning and has worked with LearningSpace course development since 1998. 
His is currently teaching these courses: Physics and Electric Circuits.

Contact phone: + 47691040 96/fax: + 4769104002

E-mail: gunnar.andersson@hiof.no http://toralf.hiof.no/ gan/

Mathias Wilichowski is a professor at University of Wismar, Germany. He received his $\mathrm{PhD}$ (Doktor-Ingenieur) at Technical University of Hamburg-Harburg in 1994, and his MSc (DiplomIngenieur) at Friedrich-Alexander-Universität Erlangen-Nürnberg.

$\mathrm{He}$ is heavily involved in the cooperation and student exchanges between Østfold University College and University of Wismar, particularly for this online student project. He has also conducted/assisted a number of online direct meetings between students from both sides. Currently he is teaching the courses in the field of Process and Environmental Engineering, among these: Sustainability Engineering; Remediation of Contaminated Soils.

Contact phone: +49 3841 753-106/Fax: +49 3841 753-132

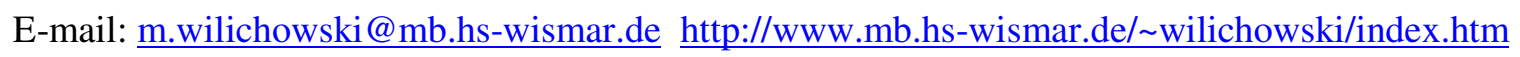

